\title{
Corrigendum
}

\section{Corrigendum to “Geometric Framework for Unified Field Theory Using Finsler Gauge Transformation"}

\author{
Mallikarjuna Yallappa Kumbar ${ }^{(D},{ }^{1}$ Sachin, ${ }^{1}$ Chowdari Kondasandra Chowdappa, ${ }^{1}$ \\ and Narasimhamurthy Senajji Kampalappa ${ }^{2}$ \\ ${ }^{1}$ Department of Mathematics, Vijaya College, Rastriya Vidyalaya Road, Bengaluru, Karnataka 560 004, India \\ ${ }^{2}$ Department of Mathematics, Kuvempu University, Shankarghatta, Karnataka 577 451, India
}

Correspondence should be addressed to Mallikarjuna Yallappa Kumbar; mallikarjunykumbar@gmail.com

Received 31 December 2017; Accepted 3 January 2018; Published 15 January 2018

Copyright (C) 2018 Mallikarjuna Yallappa Kumbar et al. This is an open access article distributed under the Creative Commons Attribution License, which permits unrestricted use, distribution, and reproduction in any medium, provided the original work is properly cited.

In the article titled "Geometric Framework for Unified Field Theory Using Finsler Gauge Transformation" [1], the name of the second author was given incorrectly as Sachin Jangir. The author's name should have been written as Sachin. The revised authors' list is shown above.

\section{References}

[1] M. Y. Kumbar, S. Jangir, C. K. Chowdappa, and N. S. Kampalappa, "Geometric framework for unified field theory using Finsler gauge transformation," Chinese Journal of Mathematics, vol. 2016, Article ID 3081840, 10 pages, 2016. 


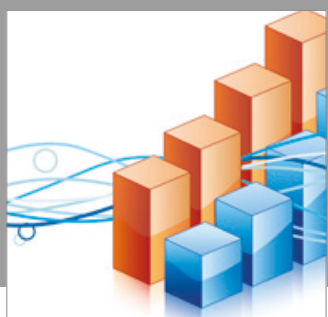

Advances in

Operations Research

vatersals

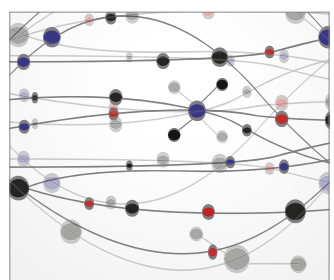

\section{The Scientific} World Journal
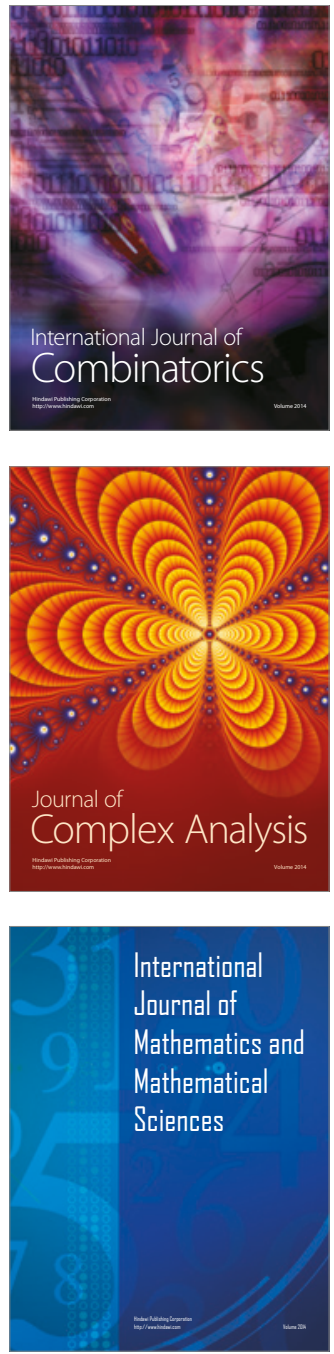
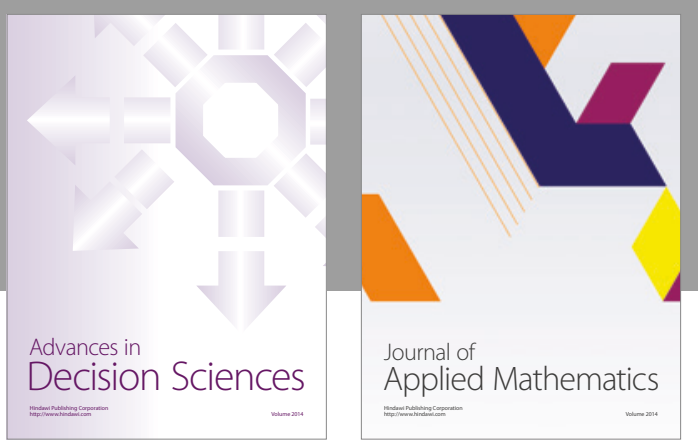

Algebra

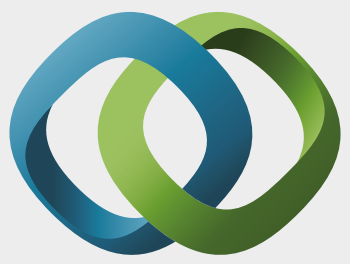

\section{Hindawi}

Submit your manuscripts at

https://www.hindawi.com
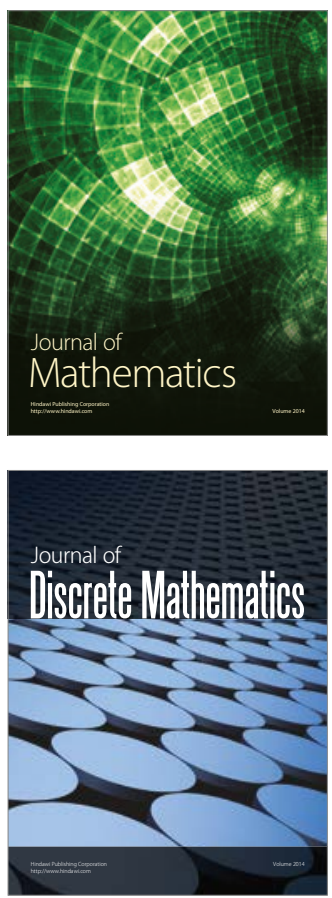

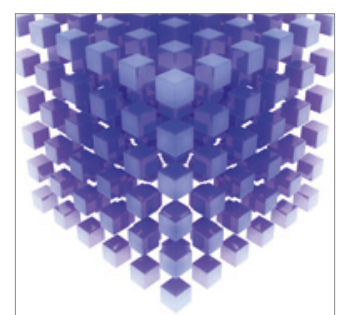

Mathematical Problems in Engineering
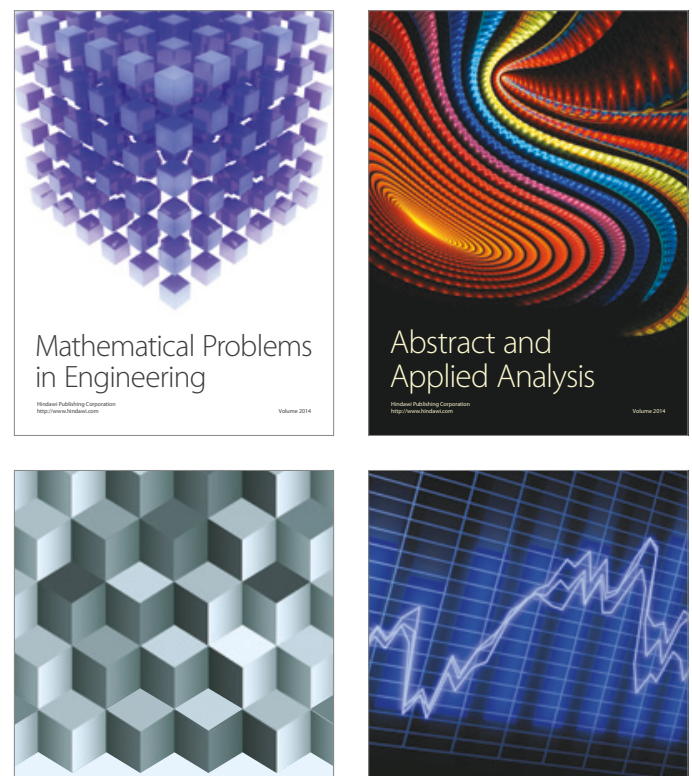

Journal of

Function Spaces

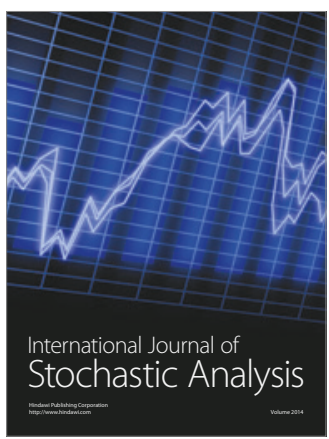

Probability and Statistics
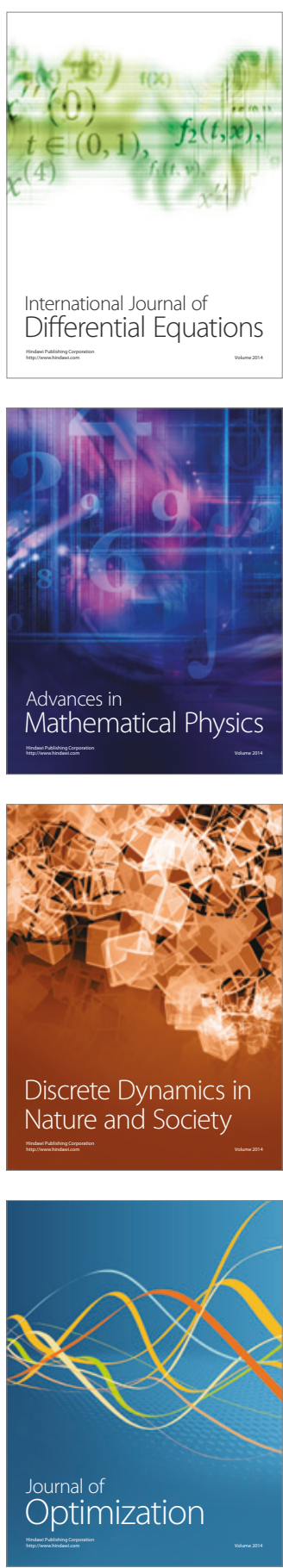